\title{
Effect of age of transfused red blood cells on neurologic outcome following traumatic brain injury (ABLE-tbi Study): a nested study of the Age of Blood Evaluation (ABLE) trial \\ Effet de l'âge des culots sanguins transfusés sur le devenir neurologique après un traumatisme cérébral (étude ABLE-tbi) : une étude imbriquée dans l'essai clinique ABLE (Age of Blood Evaluation)
}

Jessica Ruel-Laliberté, MD, MSc • Paule Lessard Bonaventure, MD, MSc • Dean Fergusson, PhD • Jacques Lacroix, MD $\cdot$ Ryan Zarychanski, MD, MSc $\cdot$ François Lauzier, MD, MSc $\cdot$ Alan Tinmouth, MD, MSc • Paul C. Hébert, MD, MSc $\cdot$ Robert Green, MD $\cdot$ Donald Griesdale, MD, MSc $\cdot$ Robert Fowler, MD, MSc • Andreas Kramer, MD $\cdot$ Lauralyn A. McIntyre, MD, MSc • David Zygun, MD, MSc • Tim Walsh, MSc, PhD • Simon Stanworth, MD, PhD • Gilles Capellier, MD • Sébastien Pili-floury, MD, PhD • Emmanuel Samain, MD • Lucy Clayton, MSc • John Marshall, MD • Giuseppe Pagliarello, MD • Elham Sabri, MSc • Xavier Neveu, MSc $\cdot$ Caroline Léger, PhD · Alexis F. Turgeon, MD, MSc on behalf of the Canadian Critical Care Trials Group

Received: 17 July 2018/Revised: 6 January 2019/Accepted: 10 January 2019/Published online: 26 February 2019

(C) Canadian Anesthesiologists' Society 2019

\begin{abstract}
Background Anemia is common in critically ill patients with traumatic brain injury, and often requires red blood cell transfusion. Studies suggest that prolonged storage
\end{abstract}

Electronic supplementary material The online version of this article (https://doi.org/10.1007/s12630-019-01326-7) contains supplementary material, which is available to authorized users.

J. Ruel-Laliberté, MD, MSc - P. Lessard Bonaventure, MD, $\mathrm{MSc} \cdot \mathrm{X}$. Neveu, MSc $\cdot \mathrm{C}$. Léger, $\mathrm{PhD}$

CHU de Québec - Université Laval Research Centre, Population Health and Optimal Health Practices Research Unit, Trauma Emergency - Critical Care Medicine, Université Laval, Quebec City, QC, Canada

D. Fergusson, $\mathrm{PhD} \cdot \mathrm{A}$. Tinmouth, MD, MSc $\cdot$ E. Sabri, MSc Clinical Epidemiology Program, Ottawa Hospital Research Institute, Ottawa, ON, Canada

J. Lacroix, MD · L. Clayton, MSc CHU Ste-Justine Research Centre, CHU Ste-Justine, Université de Montréal, Montréal, QC, Canada

R. Zarychanski, MD, MSc

Department of Internal Medicine, Sections of Critical Care Medicine, of Haematology and of Medical Oncology, Faculty of Medicine, University of Manitoba, Winnipeg, MB, Canada causes lesions of the red blood cells, including a decreased ability to carry oxygen. Considering the susceptibility of the brain to hypoxemia, victims of traumatic brain injury may thus be more vulnerable to exposure to older red blood cells.

Methods Our study aimed to ascertain whether the administration of fresh red blood cells (seven days or less) results in a better neurologic outcome compared with

F. Lauzier, MD, MSc

CHU de Québec - Université Laval Research Centre, Population Health and Optimal Health Practices Research Unit, Trauma Emergency - Critical Care Medicine, Université Laval, Quebec City, QC, Canada

Department of Anesthesiology and Critical Care Medicine, Division of Critical Care Medicine, Faculty of Medicine, Université Laval, Quebec City, QC, Canada

Department of Medicine, Faculty of Medicine, Université Laval, Quebec City, QC, Canada

P. C. Hébert, MD, MSc $\cdot$ J. Marshall, MD

Department of Medicine, Centre Hospitalier Universitaire de Montréal, Université de Montréal, Montréal, QC, Canada 
standard red blood cells in critically ill patients with traumatic brain injury requiring transfusion. The Age of Blood Evaluation in traumatic brain injury (ABLE-tbi) study was a nested study within the ABLE study (ISRCTN44878718). Our primary outcome was the extended Glasgow Outcome Scale (GOSe) at six months.

Results In the ABLE study, 217 subjects suffered a traumatic brain injury: 110 in the fresh group, and 107 in the standard group. In the fresh group, $68(73.1 \%)$ of the patients had an unfavourable neurologic outcome (GOSe $\leq 4)$ compared with $60(64.5 \%)$ in the standard group $(P=$ 0.21 ). Using a sliding dichotomy approach, we observed no overall effect of fresh red blood cells on neurologic outcome (odds ratio [OR], 1.34; 95\% confidence interval [CI], 0.72 to 2.50; $P=0.35)$ but observed differences across prognostic bands with a decreased odds of unfavourable outcome in patients with the best prognosis at baseline (OR, 0.33; 95\% CI, 0.11 to 0.96; $\mathrm{P}=0.04)$ but an increased odds in those with intermediate and worst baseline prognosis (OR, 5.88; 95\% CI, 1.66 to 20.81; $P=$ 0.006 ; and $O R, 1.67 ; 95 \% C I, 0.53$ to $5.30 ; P=0.38$, respectively).

Conclusion Overall, transfusion of fresh red blood cells was not associated with a better neurologic outcome at six months in critically ill patients with traumatic brain injury. Nevertheless, we cannot exclude a differential effect according to the patient baseline prognosis.

Trial registration ABLE study (ISRCTN44878718); registered 22 August, 2008.

\section{Résumé}

Contexte L'anémie est fréquente chez les patients en état critique ayant subi un traumatisme cérébral, et elle nécessite

\section{R. Green, MD}

Department of Emergency Medicine, Division of Critical Care

Medicine, Dalhousie University, Halifax, NS, Canada

D. Griesdale, MD, MSc

Department of Anesthesiology, Division of Critical Care

Medicine, University of British Columbia, Vancouver, BC,

Canada

R. Fowler, MD, MSc

Department of Critical Care Medicine, Sunnybrook Health Services Centre, University of Toronto, Toronto, ON, Canada

A. Kramer, MD

Department of Critical Care Medicine, Foothills Health Sciences Centre, University of Calgary, Calgary, AB, Canada

L. A. McIntyre, MD, MSc

Clinical Epidemiology Program, Ottawa Hospital Research Institute, Ottawa, ON, Canada

Department of Critical Care Medicine, The Ottawa Hospital, Ottawa, Ontario, ON, Canada souvent la transfusion de culots sanguins. Les études suggèrent qu'un entreposage prolongé provoquerait des lésions des érythrocytes, notamment une réduction de leur capacité de transport d'oxygène. Étant donné la susceptibilité du cerveau à l'hypoxémie, les victimes de traumatisme cérébral pourraient par conséquent être plus vulnérables à une exposition à des culots sanguins plus âgés. Méthode Notre étude avait pour but de vérifier si l'administration de culots sanguins frais (sept jours ou moins) entraînait un meilleur devenir neurologique que des culots sanguins standard chez des patients en état critique ayant subi un traumatisme cérébral et nécessitant une transfusion. L'étude ABLE-tbi (pour Age of Blood Evaluation in traumatic brain injury, soit 'Évaluation de l'âge du sang lors d'un traumatisme cérébral') était une étude imbriquée dans l'essai ABLE (ISRCTN44878718). Notre critère d'évaluation principal était l'Échelle de devenir de Glasgow étendue (GOSe) à six mois.

Résultats Dans l'étude ABLE, 217 patients ont subi un traumatisme cérébral. De ces patients, 110 ont reçu des culots sanguins frais, et 107 des culots sanguins standard. Dans le groupe culots sanguins frais, 68 (73,1 \%) patients ont été victimes d'un devenir neurologique défavorable (GOSe $\leq 4)$ par rapport à $60(64,5 \%)$ dans le groupe standard $(P=0,21)$. À l'aide d'une approche de dichotomie 'ajustée' (sliding dichotomy), nous n'avons observé aucun effet global des culots sanguins frais sur les devenirs neurologiques (rapport de cotes [RC], 1,34; intervalle de confiance [IC] $95 \%, 0,72$ à 2,50; $P=0,35$ ) mais avons observé des différences dans les sous-groupes de pronostic, avec une probabilité réduite de devenir défavorable chez les patients ayant un meilleur pronostic de départ (RC, 0,33; IC $95 \%, 0,11$ à 0,96; $P=0,04)$, mais

D. Zygun, MD, MSc

Department of Critical Care Medicine, University of Alberta,

Edmonton, AB, Canada

T. Walsh, MSc, PhD

University of Edinburgh, Edinburgh, UK

S. Stanworth, MD, PhD

Department of Hematology, University of Oxford, Oxford, UK

G. Capellier, MD - S. Pili-floury, MD, PhD - E. Samain, MD Department of Anesthesiology and Critical Care Medicine, Université de Besançon, Besançon, France

G. Pagliarello, MD

Department of Critical Care Medicine, The Ottawa Hospital, Ottawa, Ontario, ON, Canada

A. F. Turgeon, MD, MSc ( $\varangle)$

CHU de Québec - Université Laval Research Centre, Population Health and Optimal Health Practices Research Unit, Trauma - 
une probabilité accrue chez les patients ayant un pronostic de départ intermédiaire ou mauvais (RC, 5,88; IC $95 \%$, 1,66 à 20,81; P =0,006; et RC, 1,67; IC $95 \%, 0,53$ à 5,30; $P=0,38$, respectivement).

Conclusion Globalement, la transfusion de culots sanguins frais n'a pas été associée à un meilleur devenir neurologique après six mois chez des patients en état critique ayant subi un traumatisme cérébral. Nous ne pouvons cependant pas exclure un effet différentiel selon le pronostic de départ du patient.

Enregistrement de l'étude étude ABLE (ISRCTN4487

8718); enregistrée le 22 août 2008.

With mortality ranging from $30-50 \%$, and a third of survivors suffering major long-term neurologic impairments, severe traumatic brain injury (TBI) represents the leading cause of death and disability worldwide in young adults. ${ }^{1}$ Most critically ill patients with TBI suffer from anemia, and more than one third receive at least one red blood cell (RBC) transfusion during their intensive care unit (ICU) stay. ${ }^{2,3}$

Current practices allow RBCs to be stored for up to 42 days, with an average duration of 16-21 days. ${ }^{4}$ Recent studies have demonstrated that RBCs undergo cellular damage with prolonged storage, potentially decreasing their ability to carry oxygen. ${ }^{5-10}$ Concerns have thus been raised over the safety and efficacy of transfusing older blood. In a recent large multicentre trial in critically ill patients (Age of Blood Evaluation [ABLE] study), we observed no difference on 90-day all-cause mortality from transfusion of fresh blood (stored for seven days or less) compared with standard issued blood transfusions. ${ }^{11}$ These results were consistent with those observed in neonates in the Age of Red Blood Cells in Premature Infants (ARIPI) trial, ${ }^{12}$ as well as in hospitalized patients in the Informing Fresh vs Old Red Cell Management (INFORM) trial. ${ }^{13}$

Nevertheless, whether these findings apply to critically ill patients with TBI or any other neurocritically ill population is unclear. Considering the susceptibility of

Emergency - Critical Care Medicine, Université Laval, Quebec City, QC, Canada

e-mail: alexis.turgeon@fmed.ulaval.ca

Department of Anesthesiology and Critical Care Medicine, Division of Critical Care Medicine, Faculty of Medicine, Université Laval, Quebec City, QC, Canada

Centre de recherche du CHU de Québec - Université Laval, Population Health and Optimal Health Practices Research Unit, Trauma - Emergency - Critical Care Medicine, Hôpital de l'Enfant-Jésus, 1401, 18e Rue, Room Z-204, Quebec City, QC G1J 1Z4, Canada the injured brain to hypoxic damage, critically ill patients with TBI represent a population that is particularly vulnerable to suboptimal oxygen delivery. Nevertheless, results from two recent cohort studies did not observe a difference in brain oxygenation measures (using currently available technology), functional outcome measures, or mortality. $^{14,15}$

Considering the limited evidence on the effect of blood age in this population, we conducted the ABLE-tbi study, a planned nested study within the large scale multicentre ABLE study, with the aim of evaluating whether the use of fresh RBCs would result in a better neurologic outcome in critically ill adults with TBI.

\section{Methods}

The ABLE-tbi study is an a priori planned nested study within the ABLE study, a large multicentre blinded randomized-controlled trial (ISRCTN44878718). Critically ill adult patients on mechanical ventilation admitted to 64 ICUs in Canada, United States, United Kingdom, France, and Netherlands were enrolled in the ABLE study. ${ }^{1}$ Over a five-year period, 2,436 patients were randomized. The main objective of the ABLE study was to compare all-cause 90-day mortality following a transfusion of fresh RBC (stored for seven days or less) $v s$ a transfusion of standard RBCs (stored for up to 42 days) in critically ill adult patients. Research ethics board approval was obtained at the coordinating centre (CHU Ste-Justine on July 2008) and at each of the participating centres prior to trial initiation.

The main objective of the ABLE-tbi study was to evaluate whether the administration of fresh RBCs (seven days old or less) resulted in a better neurologic outcome compared with the administration of standard issued RBCs (up to 42 days old) in adults admitted to the ICU following a TBI. Our primary outcome measure was the extended Glasgow Outcome Scale (GOSe) ${ }^{16,17}$ at six months. Our secondary objectives were to determine the impact of blood age (fresh $v s$ standard) on ICU and hospital length of stay, and six-month mortality.

Population

Our patient population was composed of all TBI patients enrolled in the ABLE study-i.e., critically ill adult patients expected to be on mechanical ventilation for at least $48 \mathrm{hr}$, and for whom a first RBC transfusion was ordered within seven days after their admission to the ICU. In the ABLE study, we excluded brain-dead patients, patients aged $<16 \mathrm{yr}$ old, those previously enrolled in the ABLE study who had already been transfused with RBCs 
during their current hospitalization, those who had a documented terminal illness with a life expectancy of less than three months, those who had undergone routine cardiac surgical care, those who required more than one unit of uncross-matched RBCs, and those who had a known objection to blood transfusions or who were to receive autologous blood donations. Patients were also excluded in situations that posed difficulties in securing blood products, such as patients who were difficult to match, or for whom there were no RBCs with a storage time of seven days or less available in the blood bank.

\section{Patient enrolment and randomization}

During the ABLE study recruitment period (March 2009 to May 2014), ICU physicians, research nurses, and blood bank technicians screened the eligibility of patients daily whenever an RBC transfusion was ordered. As blood transfusions are often required in an urgent context, we used a deferred consent approach when it was not possible to obtain immediate consent from the patient or surrogate decision maker.

Randomization was generated by a centralized computer-generated assignment sequence, only known by a biostatistician independent of the study team. Patients were randomized at a $1: 1$ ratio to either the fresh group or the standard group. Randomization was stratified by centre and by whether the patient had an acute traumatic injury or not. Of those with acute traumatic injury $(n=372)$, about $60 \%(n=217)$ also had a TBI and were included in the ABLE-tbi study. Blood bank technicians were aware of the assignment group as they had to verify the expiration dates of blood products and record the duration of RBC storage. An opaque label was then applied by the blood bank technicians on the blood product to ensure that the medical team was blinded to treatment group allocation.

\section{Intervention}

The ABLE study compared the use of fresh RBCs (stored for seven days or less) with the use of standard RBCs (stored for up to 42 days). The standard treatment arm referred to the usual practice, especially in large centres, where the oldest compatible blood unit is often administered first to minimize waste of limited blood products. For each patient, all subsequent transfusions needed until hospital discharge, death, or up to 90 days post randomization, were consistent with the initial assignment to the "fresh" group or the "standard" RBC group. All decisions regarding transfusions and patient care were left to the discretion of the attending physicians and medical team.
Data collection and variables

We collected baseline characteristics of patients at the time of enrolment. We determined the Glasgow Coma Scale (GCS) score upon admission to the ICU. We also collected indicators of organ failure (number of dysfunctional organ systems, multi-organ dysfunction syndrome, the need for renal or circulatory support, etc.) as potential surrogate markers of impaired oxygen transport. Our primary outcome was neurologic function as assessed by the GOSe, ${ }^{16,17}$ which was evaluated by trained research nurses or research associates in person or by phone six months after the injury. All outcome assessors were blinded to the treatment allocation. We collected the number of blood units received, the acute physiology and chronic health evaluation (APACHE) II score, ${ }^{18}$ and the ICU length of stay. We obtained mortality data from patients' medical records or public national registries when patients were discharged from hospital at the time of evaluation.

\section{Statistical analysis}

We performed all analyses using an intention-to-treat principle. We used proportions ( $n$ [\%]), or median [interquartile range (IQR)] and mean (standard deviation [SD]) to describe baseline characteristics. We dichotomized the GOSe into "favourable" neurologic outcome (5-8), and "unfavourable" neurologic outcome (1-4) for our overall analysis, as per standard definitions commonly used in this patient population. ${ }^{19,20}$ We used a Chi-square test to evaluate the association between the age of RBCs and neurologic outcome (dichotomous variable) as well as a sliding dichotomy approach. ${ }^{21} \mathrm{We}$ assessed the baseline prognosis risk with the GCS and patient age to divide our study population in three prognostic bands (best, intermediate, and worst prognosis at baseline). The definition of an unfavourable outcome used in our sliding dichotomy analyses was then adapted based on the baseline risk: a score of 1-5 on the GOSe for the best, 1-4 for the intermediate, and 1-3 for the worst prognostic band, respectively. We used a log rank test comparing the Kaplan-Meier survival curves to evaluate mortality. For the overall analysis, we conducted a priori defined subgroup analyses for our primary and secondary outcomes according to the number of transfusions received ( $\leq$ three transfusions; $>$ three transfusions), the severity of the TBI (mild, moderate, or severe) as defined by the GCS on admission, age $(<40,40-50,>50 \mathrm{yr}$ old $)$, and the APACHE II score $(<20, \geq 20)$.

We performed all analyses using SAS software (version 9.3, Cary, NC, USA). A two-sided Chi-square test was used for our power analysis (type I error of 5\%). 
Considering that we did not control the number of patients to be enrolled, we estimated that 200 patients with TBI would be enrolled in the ABLE study. Based on absolute risk reduction of $20 \%$ for an unfavourable neurologic outcome (defined as a score $\leq 4$ on the GOSe), this estimated sample size provided a power from $81 \%$ to $88 \%$ depending on an observed baseline incidence of unfavourable neurologic outcome from $60 \%$ to $80 \%$, respectively.

\section{Results}

Patient characteristics and treatment assignment

Two hundred and seventeen patients with TBI were included in the ABLE-tbi study. Baseline characteristics were comparable in both groups, including illness severity [APACHE II mean (SD) score of 20.9 (7.3) in the fresh $v s$ 21.3 (6.5) in the standard group] (Table 1). Our population was mainly composed of men (71\%) with few comorbidities. The median [IQR] GCS score on ICU admission was 6 [3-10] for patients in the fresh group, as compared with 7 [3-9] for patients in the standard group $(P$ $=0.77$ ).

\section{Intervention}

Red blood cells were stored for a mean (SD) of 5.2 (3.1) days in the fresh group and 18.2 (6.3) days in the standard group $(P<0.001)$ (Table 2$)$. The overall compliance to the protocol was $96.6 \%$ for all RBC transfusions whereas $91.4 \%$ of patients in the fresh group received RBCs stored for seven days or less (Table 2). Only six patients in the fresh group and three patients in the standard group did not receive any transfusion during the study period (Table 2). Patients in the fresh group received an average of 3.7 (4.5) transfusions compared with 3.1 (3.0) transfusions in the standard group $(P=$ 0.28) (Table 2).

Table 1 Baseline characteristics of participants

\begin{tabular}{|c|c|c|c|c|}
\hline & $\begin{array}{l}\text { Fresh } \\
n=110\end{array}$ & $\begin{array}{l}\text { Standard } \\
n=107\end{array}$ & $\begin{array}{l}\text { Total } \\
n=217\end{array}$ & $P$ value \\
\hline \multicolumn{5}{|l|}{ Demographics } \\
\hline Age (yr) & $52(21)$ & $49(21)$ & $51(21)$ & 0.32 \\
\hline Gender (male); $n(\%)$ & $83(75.5)$ & $71(66.4)$ & $154(71.0)$ & 0.14 \\
\hline \multicolumn{5}{|l|}{ Glasgow Coma Score on ICU admission } \\
\hline & $6[3-10]$ & $7[3-9]$ & $7[3-10]$ & 0.77 \\
\hline \multicolumn{5}{|l|}{ APACHE II score on ICU admission } \\
\hline & $20.9(7.3)$ & $21.3(6.5)$ & $21.1(6.9)$ & 0.64 \\
\hline & $21[16-25]$ & 20 [17-27] & $20[16-26]$ & 0.48 \\
\hline Length of stay in ICU (days), ICU admission to randomization & $2.4(1.9)$ & $2.5(1.6)$ & $2.4(1.7)$ & 0.55 \\
\hline Hospital to ICU admission (days), & $0.8(3.2)$ & $1(4)$ & $0.9(3.6)$ & 0.69 \\
\hline \multicolumn{5}{|l|}{ Organ injury and support } \\
\hline MODS score & $4(2.3)$ & $4(2.1)$ & $4(2.2)$ & 0.88 \\
\hline Invasive mechanical ventilation, hours & $109(99)$ & $107(100)$ & $216(100)$ & 1.00 \\
\hline Renal replacement therapy & 0 & $1(0.9)$ & $1(0.5)$ & 0.31 \\
\hline Vasoactive support & $64(58)$ & $57(53)$ & $121(55)$ & 0.47 \\
\hline \multicolumn{5}{|l|}{ Co-morbid illnesses } \\
\hline Severe lung disease with symptoms at rest & $1(1.8)$ & 0 & $2(0.9)$ & 0.50 \\
\hline Previous myocardial infarction & $6(5.5)$ & $3(2.8)$ & $9(4.2)$ & 0.29 \\
\hline Severe heart disease with symptoms at rest & $4(3.6)$ & $2(1.9)$ & $6(2.8)$ & 0.68 \\
\hline Disabling stroke & $2(1.8)$ & $4(3.7)$ & $6(2.8)$ & 0.44 \\
\hline Chronic renal failure & $1(0.9)$ & 0 & $1(0.5)$ & 1.00 \\
\hline Diabetes, type 1 or 2 with evidence of end organ damage & $3(2.7)$ & $1(0.9)$ & $4(1.9)$ & 0.62 \\
\hline Immuno-suppressive therapy & 0 & $1(0.9)$ & $1(0.5)$ & 0.49 \\
\hline Deep venous thromboembolism & $1(0.9)$ & $2(1.9)$ & $3(1.4)$ & 0.62 \\
\hline
\end{tabular}

Data are represented as raw numbers (\%), mean (standard deviation), or median [interquartile range] as indicated. APACHE = acute physiology and chronic health evaluation; ICU = intensive care unit; MODS = multi-organ dysfunction syndrome 
Table 2 Anemia and red blood cell transfusions

$\begin{array}{llll}\begin{array}{l}\text { Fresh } \\ n=110\end{array} & \text { Standard } & \text { Total } & P \text { value } \\ n=107 & n=217 & \end{array}$

Hemoglobin concentration in intensive care unit

Pre- and post-transfusion hemoglobin level (first transfusion only)

Hemoglobin level at baseline $\left(\mathrm{g} \cdot \mathrm{dl}^{-1}\right)$

$77.9(9.3)$

$77.7(8.7)$

$77.9(9.6)$

$77.5(9.4)$

0.46

Post-randomization lowest level $\left(\mathrm{g} \cdot \mathrm{dl}^{-1}\right)$

$76.0(7.5)$

$76.8(8.2)$

0.12

Red cell transfusions post-randomization

Patients with $\geq 1$ transfusion

$104(94.6)$

$104(97.2)$

$208(95.9)$

0.50

Randomization to first transfusion (hr)

$4.3(15.7)$

8.5 (36.5)

$6.4(28.1)$

0.28

Number of red cell units/patient

$3.9(4.6)$

$3.2(3.0)$

$3.5(3.9)$

0.20

Length of storage of all red cell units (days);

$5.2(3.1)$

$18.2(6.3)$

$13.4(11.0)$

$<.01$

Compliance to research protocol

Patients

95 (91.4)

$100(96.2)$

195 (93.8)

0.15

Red cell units

$382(95.0)$

$326(98.5)$

708 (96.6)

0.01

Number of red cell transfusions/patient

Mean (SD)

3.7 (4.5)

$3.1(3.0)$

3.4 (3.9)

0.28

Median [IQR]

$2.0[1.0-4.0]$

$2.0[2.0-3.0]$

2.0 [2.0-4.0]

0.68

Total number of red cell transfusions

104 (94.6)

104 (97.2)

$208(95.9)$

0.33

Data are represented as raw numbers $(\%)$, mean (standard deviation), or median [interquartile range] as indicated

Table 3 Overall analyses

\begin{tabular}{|c|c|c|c|}
\hline Primary outcome & Fresh $(n=93)$ & Standard $(n=93)$ & $P$ value \\
\hline Unfavourable neurologic outcome (GOSe 1-4); n (\%) & $25(26.9)$ & $33(35.5)$ & 0.43 \\
\hline Median [IQR] GOSe & $3[1-5]$ & $3[1-5]$ & 0.19 \\
\hline Secondary outcomes & Fresh $(n=110)$ & Standard $(n=107)$ & \\
\hline ICU mortality & $20(18.2)$ & $14(13.1)$ & 0.35 \\
\hline Hospital mortality & $23(20.9)$ & $18(16.8)$ & 0.49 \\
\hline 6 months mortality & $32(29.1)$ & $24(22.4)$ & 0.28 \\
\hline ICU length of stay - mean (SD), days & $15.5(15.0)$ & $16.2(11.9)$ & 0.68 \\
\hline ICU length of stay - median [IQR], days & $13[8-18]$ & $13[7-21]$ & 0.48 \\
\hline Hospital length of stay - mean (SD), days & $48.3(68.0)$ & $49.7(59.5)$ & 0.88 \\
\hline Hospital length of stay - median [IQR], days & $30[19-51]$ & $33.5[19-65]$ & 0.53 \\
\hline
\end{tabular}

Data are represented as numbers $(\%)$, mean (standard deviation [SD]), or median [interquartile range (IQR)] as indicated GOSe $=$ Extended Glasgow Outcome Scale; ICU = intensive care unit

Fig. 1 Distribution of patients for each score of the GOSe. Using a sliding dichotomy approach, the overall analysis showed an odds ratio, 1.34 (95\% confidence interval, 0.72 to $2.50 ; P=0.35$ ) for an unfavourable outcome (GOSe of 1-4) for the fresh blood group. GOSe $=$ Glasgow Outcome Scale extended
Overall

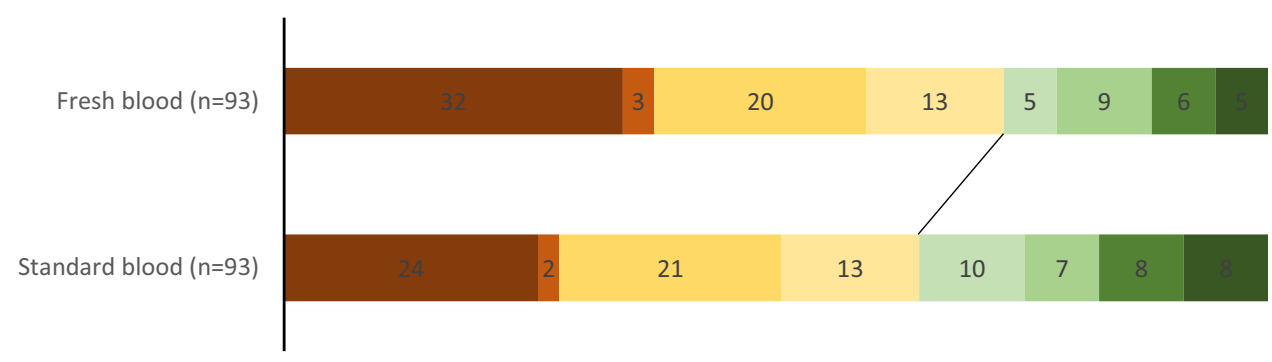


Fig. 2 Distribution of patients for each score of the GOSe for patients initially in the best prognosis band. Using a sliding dichotomy approach, the analysis showed an odds ratio, 0.33 (95\% confidence interval, 0.11 to $0.96 ; P=0.04$ ) for an unfavourable outcome (GOSe of 1-5) for the fresh blood group. GOSe $=$ Glasgow Outcome Scale extended

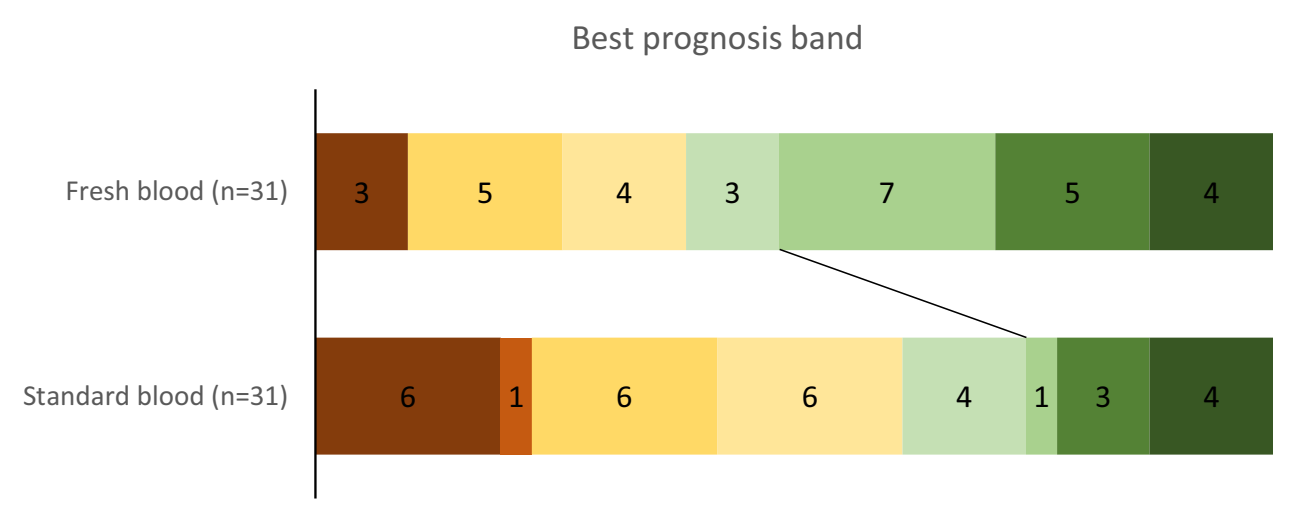

$\square 1 \square 2 \square 3 \quad 4 \quad 5 \square 6 \square 7 \square 8$

Intermediate prognosis band

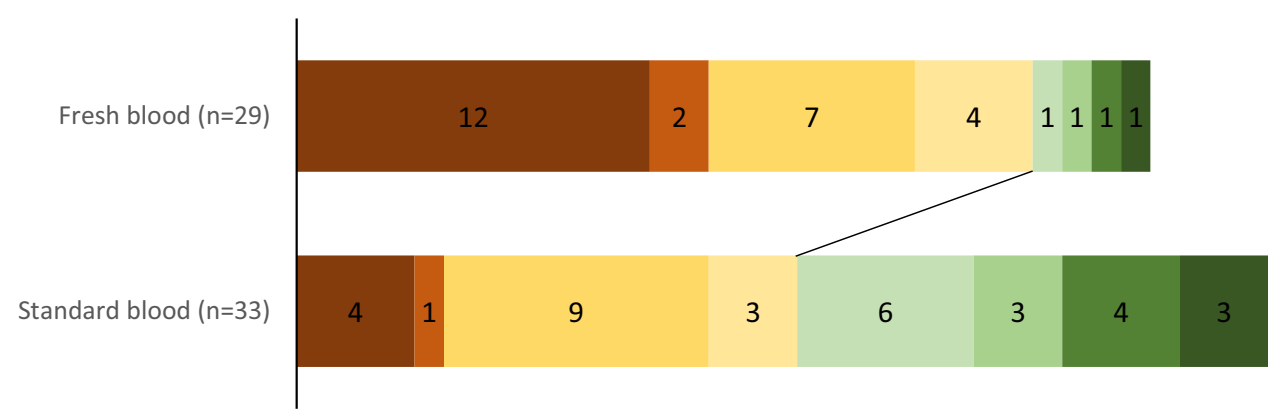

$\square 1 \square 2 \square 3 \quad 4 \square 5 \square 6 \square 7 \square 8$
Fig. 4 Distribution of patients for each score of the GOSe for patients initially in the worst prognosis band. Using a sliding dichotomy approach, the analysis showed an OR 1.67 (95\% CI, 0.53 to 5.30) for an unfavourable outcome (GOSe of 1-3) for the fresh blood group. GOSe $=$ Glasgow Outcome Scale extended; OD = odds ratio
Worst prognosis band



$\square 1 \square 2 \square 3 \quad 4 \quad 5 \square 6 \square 7 \square 8$

$2.50 ; P=0.35$ ) of the age of blood, but did observe differences across prognostic bands (in accordance with the baseline risk of the patients adjusted for GCS and age) with decreased odds of an unfavourable outcome in patients with the best prognosis at baseline (OR, 0.33; 95\% CI, 0.11 to $0.96 ; P=0.04$ ) and an increased odds in patients with an intermediate baseline prognosis (OR, 5.88; 95\% CI, 1.66 to $20.81 ; P=0.006$ ) (Figs 1 , $2,3)$. The increased odds in the most severely ill patients observed was, however, not statistically significant (OR, 1.67; 95\% CI, 0.53 to 5.30; $P=0.38$ ) (Fig. 4). The median [IQR] GOSe score for the fresh group was 3 [1-5] compared with a 
Table 4 Subgroup analyses for the Glasgow outcome scale extended

\begin{tabular}{|c|c|c|c|c|}
\hline & \multirow[b]{2}{*}{ Categories } & \multicolumn{3}{|c|}{$\begin{array}{l}\text { Unfavourable neurologic outcome } \\
\text { (GOSe 1-4) }\end{array}$} \\
\hline & & $\begin{array}{l}\text { Fresh } \\
n=93\end{array}$ & $\begin{array}{l}\text { Standard } \\
n=93\end{array}$ & $P$ value \\
\hline Overall & & $25(26.9)$ & $33(35.5)$ & 0.43 \\
\hline \multirow[t]{3}{*}{ Glasgow Coma Score on admission } & $<9$ & $13(52.0)$ & $20(64.5)$ & 0.22 \\
\hline & $9-12$ & $4(16.0)$ & $7(22.5)$ & \\
\hline & $>12$ & $8(32.0)$ & $4(13.0)$ & \\
\hline \multirow[t]{2}{*}{ Total number of red blood cell transfusions* } & $1-3$ & $15(60.0)$ & $24(77.4)$ & 0.25 \\
\hline & $>3$ & $10(40.0)$ & $7(22.6)$ & \\
\hline \multirow[t]{4}{*}{ Age (yr) } & $<40$ & $15(60.0)$ & $15(45.5)$ & 0.73 \\
\hline & 40 to $<50$ & $2(8.0)$ & $4(12.1)$ & \\
\hline & 50 to $<60$ & $3(12.0)$ & $6(18.2)$ & \\
\hline & $\geq 60$ & $5(20.0)$ & $8(24.2)$ & \\
\hline \multirow[t]{2}{*}{ APACHE II score } & $<20$ & $21(47.7)$ & $18(50.0)$ & 0.59 \\
\hline & $\geq 20$ & $4(8.2)$ & $15(26.3)$ & \\
\hline
\end{tabular}

Values are expressed as $n(\%)$

*7 out of 186 patients who had a GOSe score did not receive a red blood cell transfusion

GOSe $=$ extended Glasgow Outcome Scale; APACHE = acute physiology and chronic health evaluation

score of 3 [1-5] for the standard group $(P=0.19)$ (Table 3). Subgroup analyses based on age, total number of RBC transfusions received, and APACHE II score, did not yield any statistically significant results (Table 4). The severity of the TBI (mild, moderate, or severe) was not associated with any significant difference in the GOSe score between groups.

\section{Secondary outcomes}

In-hospital and ICU mortality did not differ between intervention groups. At six months post randomization, 32 patients in the fresh group had died compared with 24 patients in the standard group $(P=0.25)$ (Table 3). Stratified analyses based on age, GCS score, total number of RBC transfusions received, and APACHE II score did not yield significant results for either of the secondary outcomes (available as Electronic Supplementary Material [ESM], eTable 1). No significant differences were noted between groups for complications and concomitant clinical conditions (available as ESM, eTable 2). The mean (SD) ICU length of stay was comparable between the fresh blood group and the standard blood group [15.5 (15.0) vs 16.2 (11.9) days, respectively; $P=0.68]$.

\section{Discussion}

In our study, we observed that transfusion of fresh blood (stored for seven days or less) did not improve the neurologic outcome at six months compared with transfusion of standard-issue blood. We observed, however, differences across prognostic bands and cannot exclude a differential effect according to the patient baseline prognosis. We also found that ICU, in-hospital, and six-month mortality, as well as the length of stay in the ICU, were comparable between the groups. Adjustments for several potential confounders, including TBI severity, yielded similar results.

The results of our study are consistent with those of the ABLE study cohort conducted in the overall critically ill adult population. ${ }^{11}$ In the ABLE study, the 90-day-allcause mortality rate was similar between the intervention groups. In addition, no significant benefit of transfusing fresh RBCs was found over standard RBC transfusions with regard to clinically relevant outcomes related to oxygen impairments, such as duration of respiratory, hemodynamic, or renal support. Our results are also consistent with those of a multicentre randomizedcontrolled trial in critically ill low birth weight premature infants, where no association was found between the age of blood and the occurrence of major comorbidities, including death. ${ }^{12}$ Moreover, no association was found between the duration of blood storage (less than ten days vs more than 21 days) and a change in the Multiple Organ Dysfunction score in a similar study conducted on patients undergoing complex cardiac surgery. ${ }^{22}$ Although those authors studied the rate of organ failure in the cardiac surgery population, the heart is, as the brain, another organ that is sensitive to hypoxic damage. In an overall population of patients admitted to hospital regardless of the diagnosis and disease 
severity, the authors of a recent large randomizedcontrolled trial had similar findings. ${ }^{13}$ Nevertheless, these studies looked at mortality, a suboptimal outcome in TBI patients where long-term function is what patients and relatives are wary of.

As suggested in a systematic review of 21 randomized and observational studies, which included a total of 409,966 patients, transfusion of older RBCs resulted in a $16 \%$ increased risk of mortality compared with transfusion of fresh RBCs. ${ }^{23}$ This difference was also observed in a subgroup analysis performed on trauma patients $(n=6$ studies), in which TBI patients were underrepresented. The majority of included studies had an observational design, which may have introduced unintentional biases, such as the selection of fresher RBCs for patients with the best predictable outcome.

No previous randomized-controlled trial comparing the age of RBCs was ever conducted in TBI patients. A recent post hoc analysis of a subgroup of patients from a randomized-controlled trial on transfusion thresholds and erythropoietin in severe TBI was recently published. ${ }^{14}$ In this cohort study, the authors observed no association between the age of RBCs and jugular venous oxygen saturation, brain tissue oxygenation, GOSe at six months, and mortality when treating RBCs as a continuous variable, or when comparing patients transfused with fresh RBCs (less than 14 days) to those transfused with older RBCs (14 days or older). Importantly, patients were not randomized according to the age of blood, therefore in the case of multiple transfusions, it is possible that the same patient received both fresh and older blood. The results from another observational study comparing patients who received fresh (less than 19 days) $v s$ old RBCs also showed no difference in cerebral tissue oxygen pressure. ${ }^{15}$

\section{Strengths and limitations}

Strengths of our study include its multicentre population from different sites across different countries, the fact that it was nested within a large scale multicentre randomized trial conducted with excellent methodological rigor, and followed a planned protocol. Our primary outcome is based on long-term neurologic recovery at six months measured by the GOSe, which is the most reliable and rigorous scale available for evaluating neurologic functional outcome in TBI. Participants, treating team, and outcome assessors were blinded to the study intervention. The ABLE-tbi study is the largest prospective comparative study in a neurocritically ill population, and one of the largest studies on transfusion in a population of TBI patients.

The results of our study must be interpreted with several limitations in mind. Although the ABLE-tbi study was an $a$ priori planned nested study, the initial ABLE study was not designed to specifically assess patients with TBI. Many factors related to neurologic outcomes (e.g., elevated intracranial pressure, pupillary reactivity, head computed tomography scan results, etc.) were not recorded, and thus could not be included in the analyses. Also, the randomization of patients was not stratified based on the diagnosis of TBI, but rather by whether or not a trauma was their primary admission diagnosis; patients in the ABLEtbi study were thus not necessarily randomized to the intervention. Nevertheless, most trauma patients had a TBI, thus most patients were randomized. Finally, the number of patients for which we did not have a measure of GOSe at six-month was almost $15 \%$ of the sample. Nevertheless, this rate of lost to follow-up is fairly common and comparable to a recent large trial in this population. ${ }^{19}$

\section{Conclusion}

In summary, the results of our study show that the use of fresh RBC compared with standard issued $\mathrm{RBC}$ in critically ill patients with TBI receiving transfusion during their ICU stay does not improve their neurologic functional outcome at six months. Nevertheless, we observed differences across prognostic bands and cannot exclude a differential effect according to the patient baseline prognosis toward a lower risk of unfavourable outcome with fresh blood in patients with a better prognosis at baseline and a potential increased risk in those with a more severe baseline prognosis. Future trials should explore the potential differential effects of the age of blood transfused according to the disease severity and baseline prognosis in this population.

Acknowledgements We want to thank the Grants and Manuscript Committee of the Canadian Critical Care Trials Group for the internal review process prior to submission.

Conflicts of interest None declared.

Editorial responsibility This submission was handled by Dr. Hilary P. Grocott, Editor-in-Chief, Canadian Journal of Anesthesia.

Authors contributions Jessica Ruel-Laliberté, Dean Fergusson, Jacques Lacroix, Ryan Zarychanski, François Lauzier, Alan Tinmouth, and Alexis F. Turgeon were involved in study concept and design. Jessica Ruel-Laliberté, Dean Fergusson, Jacques Lacroix, Ryan Zarychanski, Alan Tinmouth, Paul C. Hébert, Robert Green, Donald Griesdale, Robert Fowler, Andreas Kramer, Lauralyn A. McIntyre, David Zygun, Tim Walsh, Simon Stanworth, Gilles Capellier, Sébastien Pili-floury, Emmanuel Samain, Lucy Clayton, John Marshall, Giuseppe Pagliarello, and Alexis F. Turgeon were involved in acquisition of the data. Jessica Ruel-Laliberté, Paule Lessard Bonaventure, Dean Fergusson, Jacques Lacroix, Ryan Zarychanski, Alan Tinmouthi, Paul C. Hébert, Robert Green, Donald Griesdale, Robert Fowler, Andreas Kramer, Lauralyn A. McIntyre, David Zygun, Tim Walsh, Simon Stanworth, Gilles 
Capellier, Sébastien Pili-floury, Emmanuel Samain, Lucy Clayton, John Marshall, Giuseppe Pagliarello, Caroline Léger, and Alexis F. Turgeon were involved in the interpretation of data. Jessica RuelLaliberté, Caroline Léger, and Alexis F. Turgeon were involved in drafting the manuscript. Elham Sabri, Xavier Neveu, and Alexis F. Turgeon were involved in the statistical analyses. All authors were involved in critical revision of the manuscript. Alexis F. Turgeon supervised the study.

Funding Dr. Turgeon is the chairholder of the Canada Research Chair in Critical Neurology and Trauma. Drs. Lauzier and Moore are recipients of a research career award from the Fonds de Recherche $d u$ Québec - Santé (FRQS). Dr. Hébert holds the Héma-Québec - Bayer Endowed Chair in Transfusion Medicine from Université de Montréal. Drs. Turgeon, Lauzier, and Moore are supported by the Traumatology Research Consortium of the FRQS. Dr. Zarychanski and Turgeon were recipients of a New Investigator Award from the Canadian Institutes of Health Research (CIHR) when this work was conducted.

\section{References}

1. Lacroix J, Hebert P, Fergusson D, et al. The Age of Blood Evaluation (ABLE) randomized controlled trial: study design. Transfus Med Rev 2011; 25: 197-205.

2. Boutin A, Chasse M, Shemilt M, et al. Red blood cell transfusion in patients with traumatic brain injury: a systematic review and meta-analysis. Transfus Med Rev 2016; 30: 15-24.

3. Boutin A, Moore L, Lauzier F, et al. Transfusion of red blood cells in patients with traumatic brain injuries admitted to Canadian trauma health centres: a multicentre cohort study. BMJ Open 2017; 7: e014472.

4. Clarke G. Guide de la Pratique Transfusionnelle - Chapitre 2. Les composants sanguins. Société canadienne du sang, 2017. Available from URL: https://professionaleducation.blood.ca/fr/ transfusion/guide-clinique/les-composants-sanguins (accessed January 2019).

5. Tinmouth A, Fergusson D, Yee IC, Hebert PC; ABLE Investigators; Canadian Critical Care Trials Group. Clinical consequences of red cell storage in the critically ill. Transfusion 2006; 46: 2014-27.

6. Aubron C, Nichol A, Cooper DJ, Bellomo R. Age of red blood cells and transfusion in critically ill patients. Ann Intensive Care 2013; 3: 2.

7. Bennett-Guerrero E, Veldman TH, Doctor A, et al. Evolution of adverse changes in stored RBCs. Proc Natl Acad Sci USA 2007; 104: 17063-8.

8. Stapley $R$, Owusu B, Brandon A, et al. Erythrocyte storage increases rates of $\mathrm{NO}$ and nitrite scavenging: implications for transfusion-related toxicity. Biochem J 2012; 446: 499-508.
9. D'Alessandro A, Liumbruno G, Grazzini G, Zolla L. Red blood cell storage: the story so far. Blood Transfus 2010; 8: 82-8.

10. Khan SY, Kelher MR, Heal JM, et al. Soluble CD40 ligand accumulates in stored blood components, primes neutrophils through CD40, and is a potential cofactor in the development of transfusion-related acute lung injury. Blood 2006; 108: 2455-62.

11. Lacroix J, Hebert PC, Fergusson DA, et al. Age of transfused blood in critically ill adults. N Engl J Med 2015; 372: 1410-8.

12. Fergusson DA, Hebert P, Hogan DL, et al. Effect of fresh red blood cell transfusions on clinical outcomes in premature, very low-birth-weight infants: the ARIPI randomized trial. JAMA 2012; 308: 1443-51.

13. Heddle NM, Cook RJ, Arnold DM, et al. Effect of short-term vs. long-term blood storage on mortality after transfusion. N Engl J Med 2016; 375: 1937-45.

14. Yamal JM, Benoit JS, Doshi P, et al. Association of transfusion red blood cell storage age and blood oxygenation, long-term neurologic outcome, and mortality in traumatic brain injury. $\mathbf{J}$ Trauma Acute Care Surg 2015; 79: 843-9.

15. Leal-Noval SR, Munoz-Gomez M, Arellano-Orden $V$, et al. Impact of age of transfused blood on cerebral oxygenation in male patients with severe traumatic brain injury. Crit Care Med 2008; 36: 1290-6.

16. Jennett B, Bond $M$. Assessment of outcome after severe brain damage. Lancet 1975; 1: 480-4.

17. Jennett B, Snoek $J$, Bond MR, Brooks $N$. Disability after severe head injury: observations on the use of the Glasgow Outcome Scale. J Neurol Neurosurg Psychiatry 1981; 44: 285-93.

18. Knaus WA, Draper EA, Wagner DP, Zimmerman JE. APACHE II: a severity of disease classification system. Crit Care Med 1985; 13: 818-29.

19. Cooper DJ, Nichol AD, Bailey M, et al. Effect of early sustained prophylactic hypothermia on neurologic outcomes among patients with severe traumatic brain injury: the POLAR randomized clinical trial. JAMA 2018; 320: 2211-20.

20. Andrews PJ, Sinclair HL, Rodriguez A, et al. Hypothermia for intracranial hypertension after traumatic brain injury. $\mathrm{N}$ Engl $\mathrm{J}$ Med 2015; 373: 2403-12.

21. Murray GD, Barer D, Choi S, et al. Design and analysis of phase III trials with ordered outcome scales: the concept of the sliding dichotomy. J Neurotrauma 2005; 22: 511-7.

22. Steiner ME, Ness PM, Assmann SF, et al. Effects of red-cell storage duration on patients undergoing cardiac surgery. N Engl J Med 2015; 372: 1419-29.

23. Wang D, Sun J, Solomon SB, Klein HG, Natanson C. Transfusion of older stored blood and risk of death: a meta-analysis. Transfusion 2012; 52: 1184-95.

Publisher's Note Springer Nature remains neutral with regard to jurisdictional claims in published maps and institutional affiliations. 